\title{
Studi Komparatif Daya DUKung PONDAsi TIANg DENGAN TEORI MEYERHOFF TERHADAP TEORI L'DECOURT BERDASAR HASIL UJI N-SPT DI SURABAYA TIMUR
}

\author{
Isnaniati $^{1)}$, Defi.. ${ }^{2)}$ \\ ${ }^{1)}$ Program Studi Teknik Sipil , Fakultas Teknik, \\ Universitas Muhammadiyah Surabaya \\ Jl. Sutorejo No.59 Surabaya, Telp 031-3811966 \\ Email: isnaniati65@gmail.com \\ ${ }^{2)}$ Test Tanah Engineering
}

\begin{abstract}
The condition of the land near the shore caused the land on this project site to be a soil of silt sand. With these conditions it is necessary to evaluate the bearing capacity because the bearing capacity is an absolute requirement that must be considered in the planning of a secure foundation. By knowing the bearing capacity we can plan the load that is given so that the ultimate bearing capacity is not exceeded because if the load that works beyond the ultimate supporting capacity will result in structural failure. The number of power support theorists forced planners to be able to compare the theory where the optimal bearing capacity is used for foundation planning.

Calculation of bearing capacity of pile is done by using two theories of Mayerhoof and L 'Decourt theory. Two data points of drill NSPT were used on the land of At-tauhid UM-Surabaya building located in East Surabaya. By providing variations the pole depth $(20,22$ and $24 \mathrm{~m})$ and selected square sectional shape $(\mathrm{s}=0.5 \mathrm{~m})$ with safety factor 3 it can be calculated the bearing capacity of the end (Qp), the bearing capacity of the blanket (Qs), the bearing capacity utimate (Qult) as well as the bearing capacity of the permit (Qall) in order to compare the bearing capacity of the most effective of both theories. From the research results obtained the value of the average bearing capacity based on the value of comparison between L'Decourt to Mayerhof in DB-1 is Qp $=0.96$, Qs $=2$, Qult $=1.28$, Qall $=1.28$ and at DB-2 is Qp $=0.96$, Qs $=1.99$, Qult $=1.21$, Qall $=1.21$.
\end{abstract}

Keywords: Bearing capacity, N-SPT, Mayerhoof, L 'Decourt.

\begin{abstract}
Abstrak
Kondisi tanah dekat pantai menyebabkan tanah dilokasi proyek ini merupakan tanah lanau kepasiran. Dengan kondisi tersebut perlu dilakukan evaluasi terhadap daya dukungnya karena daya dukung merupakan syarat mutlak yang harus diperhatikan dalam perencanaan pondasi yang aman. Dengan mengetahui daya dukung kita dapat merencanakan beban yang di berikan agar daya dukung ultimate yang ada tidak dilampaui karena apabila beban yang bekerja melampaui daya dukung ultimatenya akan berakibat kegagalan struktur. Banyaknya teori daya dukung memaksa perencana untuk bisa membandingkan teori daya dukung mana yang optimal digunakan utuk perencanaan pondasi.

Perhitungan daya dukung tiang dilakukan dengan menggunakan dua teori yaitu teori Mayerhoof dan L' Decourt . Digunakan 2 data titik bor NSPT pada tanah gedung At-tauhid UM-Surabaya yang berlokasi di Surabaya Timur . Dengan memberikan variasi kedalaman tiang $(20,22$ dan $24 \mathrm{~m})$ dan dipilih bentuk penampang tiang persegi $(\mathrm{s}=0.5 \mathrm{~m})$ dengan faktor keamanan 3 maka dapat dihitung besarnya daya dukung ujung (Qp), daya dukung selimut (Qs), daya dukung utimate (Qult) maupun daya dukung ijin (Qall) agar dapat dibandingkan daya dukung mana yang paling efektif dari kedua teori tersebut. Dari hasil penelitian diperoleh nilai daya dukung rata-rata berdasarkan nilai perbandingan antara $L$ 'Decourt terhadap Mayerhof pada DB-1 adalah Qp= 0.96 , Qs $=$ 2, Qult=1.28, Qall= 1.28 dan pada DB-2 adalah $\mathrm{Qp}=0.96, \mathrm{Qs}=1.99$, Qult=1.21, Qall $=1.21$.
\end{abstract}

Kata kunci : Daya dukung, N-SPT, Mayerhoof, L’ Decourt.

\section{PENDAHULUAN}

Surabaya Timur yang merupakan kota pesisir yang masuk dalam wilayah administratif Kota Surabaya di propinsi Jawa Timur. Kondisi tanah di wilayah ini khususnya kampus UM-Surabaya umumnya berupa tanah lunak lempung sampai dengan lanau berpasir. Kondisi tanah pada proyek di gedung 13 lantai UM-Surabaya merupakan tanah lanau kepasiran dengan menggunakan uji N-SPT.

Banyaknya tersedianya teori daya dukung memaksa perencana untuk bisa membandingkan teori daya dukung mana yang optimal digunakan utuk perencanaan pondasi. Pada penelitian ini digunakan pondasi tiang pancang bentuk penampang persegi berdasarkan hasil penelitian (isnaniati, 2016, hal 1-6) dengan metoda NSPT diperoleh bahwa bentuk penampang persegi mempunyai jumlah tiang (n) paling sedikit, daya dukung ijin (Qall) paling besar dibandingkan bentuk penampang lingkaran, bentuk penampang segi enam dan hasil penelitian (isnaniati, 2017, hal 21-27) dengan metoda CPT diperoleh bahwa bentuk penampang persegi mempunyai beban max (Qmax) terbesar, daya dukung ijin (Qall) terbesar dibandingkan bentuk penampang lingkaran, bentuk penampang segi enam . Agar diperolah daya dukung yang optimal perlu dilakukan studi komparativ dengan beberapa teori metoda NSPT yaitu teori Mayerhof dan $L^{\prime}$ Decourt, sehingga diketahui besarnya daya dukung ujung, daya dukung selimut, daya dukung ultimate dan daya dukung ijinnya .Hal ini karena daya dukung merupakan syarat utama yang harus dipenuhi dalam perencanaan pondasi . Pondasi dikatakan aman apabila beban yang diteruskan oleh pondasi ke tanah tidak melampaui kekuatan tanah yang bersangkutan. Karena apabila kekuatan tanah dilampaui maka akan terjadi penurunan struktur bangunan yang rawan mengalami keruntuhan/ kegagalan. 
Penyelidikan berdasarkan standard penetrasi test (SPT) bertujuan untuk mendapatkan gambaran lapisan tanah berdasarkan jenis dan warna tanah melalui pengamatan secara visual, sifat-sifat tanah, karakteristik tanah.. Metoda NSPT yang digunakan adalah berdasarkan teori Mayerhof dan L'Decourt. Dari ke dua teori tersebut diteliti mana teori yang paling optimal dalam memberikan nilai faktor keamanan.

Rumusan masalah yang dapat dirumuskan pada penulisan tugas akhir ini adalah sebagai berikut :

1. Bagaimana daya dukung ujung, daya dukung selimut, daya dukung ultimate, daya dukung ijin pondasinya dari teori Mayerhof dan L'Decourt.

2. Teori manakah yang paling efektif digunakan untuk perencanaan pondasi dari ke dua teori tersebut.

Tujuan dari penelitian ini adalah diperolehnya gambaran tentang besarnya daya dukung pondasi dari teori Mayerhof dan teori L' Decourt sehingga bisa digunakan sebagai pedoman perencanaan pondasi tiang untuk memilih teori manakah yang memberikan daya dukung yang paling optimal.

\section{TINJAUAN PUSTAKA}

Pondasi merupakan suatu bagian dari konstruksi bangunan yang bertugas meletakan bangunan dan meneruskan beban bangunan diatasnya ke dasar tanah yang cukup kuat mendukungnya (Hardiyatmo, 2002). Pondasi tiang pancang sebagai pondasi bangunan digunakan apabila tanah yang mempunyai daya dukung yang cukup untuk memikul berat bangunan yang bekerja berada pada lapisan yang sangat dalam dari permukaan tanah.

\section{Standard Penetration Test (SPT)}

Suatu metode uji yang dilaksanakan bersamaan dengan pengeboran untuk mengetahui, baik perlawanan dinamik tanah maupun pengambilan contoh terganggu dengan teknik penumbukan. Uji $S P T$ terdiri atas uji pemukulan tabung belah dinding tebal ke dalam tanah, disertai pengukuran jumlah pukulan untuk memasukkan tabung belah sedalam $300 \mathrm{~mm}$ vertikal. Dalam sistem beban jatuh ini digunakan palu dengan berat $63,5 \mathrm{~kg}$, yang dijatuhkan secara berulang dengan tinggi jatuh 0,76 m. Pelaksanaan pengujian dibagi dalam tiga tahap, yaitu berturut-turut setebal $150 \mathrm{~mm}$ untuk masing-masing tahap. Tahap pertama dicatat sebagai dudukan, sementara jumlah pukulan untuk memasukkan tahap ke-dua dan ke-tiga dijumlahkan untuk memperoleh nilai pukulan $\mathrm{N}$ atau perlawanan SPT (dinyatakan dalam pukulan/0,3 m).

\section{Klasifikasi Tanah}

Klasifikasi tanah dengan menggunakan USCS (Unified Soil Classification System) merupakan metode klasifikasi tanah yang cukup banyak digunakan dalam bidang geoteknik. Klasifikasi ini diusulkan oleh A. Cassagrande pada tahun 1942 dan direvisi pada tahun 1952 oleh The Corps of ENgeneers and The US Bureau of Reclamation. Pada prinsipnya menurut metode ini, ada 2 pembagian jenis tanah yaitu tanah berbutir kasar (kerikil dan pasir) dan tanah berbutir halus (lanau dan lempung).
Tanah digolongkan dalam butiran kasar jika lebih dari $50 \%$ tertahan di atas saringan no. 200. Sementara itu tanah digolongkan berbutir halus jika lebih dari 50\% lolos dari saringan no. 200. Selanjutnya klasifikasi yang lebih detail lagi dapat menggunakan table 1 dan gambar.1 USCS berikut ini .

\section{Tabel.1.Klasifikasi tanah berdasar USCS}

\begin{tabular}{|c|c|c|c|}
\hline Jenis & Simbol & Nama Kelompok & Kriteria \\
\hline \multirow{4}{*}{$\begin{array}{c}\text { Lanau dan } \\
\text { lempung } \\
\text { dengan } \\
\text { batas cair, } \\
\text { LL }< \\
50 \%\end{array}$} & MI & $\begin{array}{c}\text { Lanau inorganik dan pasir } \\
\text { sangat halus atau pasir } \\
\text { halus berlanau atau } \\
\text { berlempung }\end{array}$ & $\begin{array}{c}\text { PI }<4 \text { atau berada di } \\
\text { bawah garis-A dalam } \\
\text { Grafik Plastisitas } \\
\text { (Gambar 1). }\end{array}$ \\
\hline & $\mathrm{CL}$ & $\begin{array}{c}\text { Lempung inorganik } \\
\text { dengan plastisitas rendah } \\
\text { hingga sedang, lempung } \\
\text { berkeriki1, lempung } \\
\text { berpasir, lempung } \\
\text { berlanau, lempung kurus } \\
\text { (clean clays) }\end{array}$ & $\begin{array}{l}\text { PI > } 7 \text { dan berada pada } \\
\text { atau di bawah garis-A } \\
\text { dalam Grafik } \\
\text { Plastisitas (Gambar 1). }\end{array}$ \\
\hline & $\begin{array}{l}\text { CL- } \\
\text { MI }\end{array}$ & $\begin{array}{c}\text { Lanau berlempung } \\
\text { inorganik, dengan pasir } \\
\text { halus atau sedikit kerikil. }\end{array}$ & $\begin{array}{c}\text { PI berada dalam } \\
\text { daerah yang diarsir } \\
\text { (hatched area) dalam } \\
\text { Gambar } 1 .\end{array}$ \\
\hline & OL & $\begin{array}{l}\text { Lanau organik dan } \\
\text { lempung berlanau organik } \\
\text { dengan plastisitas rendah }\end{array}$ & 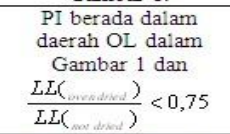 \\
\hline \multirow{3}{*}{$\begin{array}{c}\text { Lanau dan } \\
\text { lempung } \\
\text { dengan } \\
\text { batas cair } \\
\text { LL > } \\
50 \%\end{array}$} & $\mathrm{MH}$ & $\begin{array}{c}\text { Lanau inorganik atau } \\
\text { pasir halus diatomae, } \\
\text { lanau } \\
\text { Elastis }\end{array}$ & $\begin{array}{c}\text { PI berada dibawah } \\
\text { garis-A dalam Grafik } \\
\text { Plastisitas (Gambar 1) }\end{array}$ \\
\hline & $\mathrm{CH}$ & $\begin{array}{c}\text { Lempung inoragnik } \\
\text { dengan plastisitas tinggi, } \\
\text { lempung gemuk (fat } \\
\text { clays) }\end{array}$ & $\begin{array}{l}\text { PI berada diatas garis- } \\
\text { A dalam Grafik } \\
\text { Plastisitas (Gambar. 1) }\end{array}$ \\
\hline & $\mathrm{OH}$ & $\begin{array}{l}\text { Lempung organik dengan } \\
\text { plastisitas sedang } \\
\text { sampai tinggi }\end{array}$ & $\begin{array}{c}\text { PI berada dalam } \\
\text { daerah OH dalam } \\
\text { Gambar } 1 \\
\quad \text { dan } \\
\frac{L L(\quad \text { aneadied })}{L L(}<0,75\end{array}$ \\
\hline $\begin{array}{c}\text { Tanah } \\
\text { dengan } \\
\text { kadar } \\
\text { organik } \\
\text { tinggi }\end{array}$ & $\mathrm{Pt}$ & $\begin{array}{c}\text { Gambut (peat), dan tanah } \\
\text { lain kandungan organik } \\
\text { Tinggi }\end{array}$ & \\
\hline
\end{tabular}

Sumber : Bowles

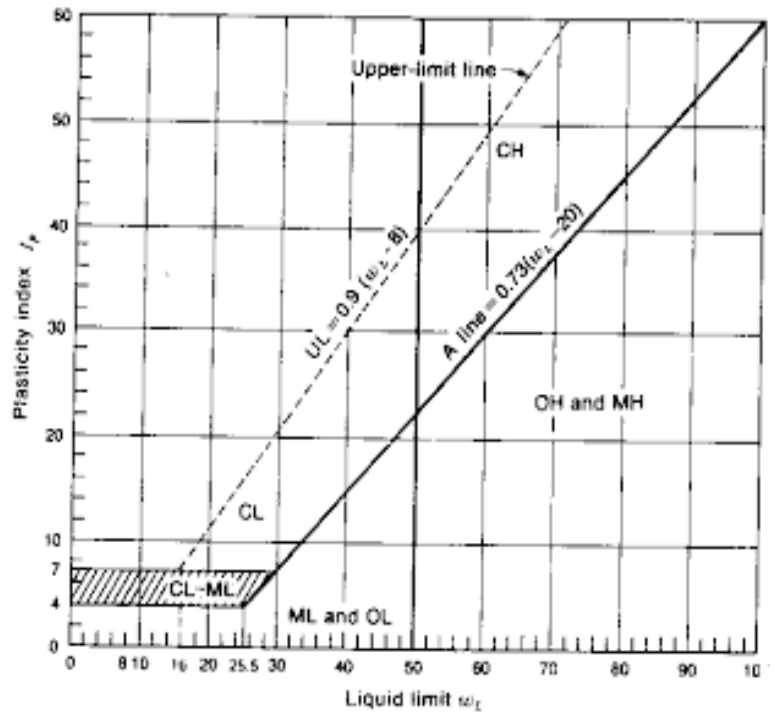

Gambar.1. Grafik Hubungan LL dan PI (sumber Bowles)

Berikut ciri-ciri nya :

1. Lanau (Silt) Tanah lanau memiliki kekuatan geser undrained yang rendah yaitu sekitar 10 - 20 Kpa untuk tanah lanau yang lunak, dan 4 - $10 \mathrm{Kpa}$ untuk tanah lanau yang sangat lunak. Tingkat plastisitasnya rendah 
dan memiliki permeabilitas yang tinggi sehingga penurunan konsolidasi terjadi begitu cepat.

2. Lempung (Clay) Tanah lempung memiliki tegangan geser dan permeabilitas yang rendah, namun plastisitas tanah lempung yang tinggi. Karena koefisien permeabilitas tanah lempung yang rendah, penurunan konsolidasi tanah lempung terjadi sangat lama.

3. Tanah Organik (Tanah Gambut) Tanah organik biasanya berbau tumbuhan atau kayu yang sudah membusuk. Tanah ini disebut sebagai Tanah gambut bila tingkat organiknya mencapai lebih dari $75 \%$ dan memiliki kadar air alamiah yang sangat tinggi. Tanah gambut merupakan salah satu tanah yang sulit sekali untuk diperbaiki.

Tabel 2. Konsistensi Tanah Dominan Lempung

\begin{tabular}{|c|c|c|c|c|c|}
\hline Consistency & $\begin{array}{c}\text { Very } \\
\text { Soft }\end{array}$ & Soft & Medium & Stiff & $\begin{array}{c}\text { Very } \\
\text { Stiff }\end{array}$ \\
\hline SPT (N) & $\begin{array}{c}0- \\
2,5\end{array}$ & $\begin{array}{c}2,5- \\
5,0\end{array}$ & $5-10$ & $\begin{array}{c}10- \\
20\end{array}$ & $20-40$ \\
\hline $\begin{array}{c}\text { Sondir } \\
\left(\mathrm{kg} / \mathrm{cm}^{2}\right)\end{array}$ & $0-5$ & $\begin{array}{c}5- \\
10\end{array}$ & $10-20$ & $\begin{array}{c}20- \\
40\end{array}$ & $40-80$ \\
\hline
\end{tabular}

Sumber: Prof.Ir.Indrasurya.B.Mochtar,MSc, PhD, 2010

\section{Daya Dukung Pondasi Tiang Berdasarkan Uji SPT}

Penentuan daya dukung pondasi tiang dengan menggunakan data SPT antara lain diberikan oleh Mayerhof dan L' Decourt

Daya dukung pondasi tiang adalah merupakan penjumlahan daya dukung ujung $(\mathrm{Qp})$ dan daya dukung selimut (Qs) :

$$
\text { Qult }=\text { Qp + Qs }
$$

\section{Metode Mayerhof}

Korelasi daya dukung tiang dengan hasil uji SPT yang diusulkan oleh Meyerhof (1956) (sumber: Herman Wahyudi) berdasarkan penyelidikan yang dilakukan pada pondasi tiang pancang yang tertanam pada tanah lempung berpasir halus.

$$
\mathrm{Qu}=\mathrm{m} \cdot \mathrm{Np} \cdot \mathrm{Ap}+\mathrm{n} \cdot \tilde{\mathrm{N}} \cdot \mathrm{As}
$$

Meyerhof menganjurkan nilai $\mathrm{m}=40$ untuk koefisien perlawanan ujung tiang dan nilai $\mathrm{n}=0,2$ untuk koefisien perlawanan gesek tiang pada tanah lempung kepasiran, sedangkan $\mathrm{n}=0,5$ pada tanah kelanauan sehingga,

\section{- Tanah lempung kepasiran}

Daya Dukung Ujung (Qp) :

$$
\mathrm{Qp}=40 . \mathrm{Np} \text {. Ap }
$$

Daya Dukung Selimut :

Sehingga ,

$$
\mathrm{Qs}=0,2 \cdot \tilde{\mathrm{N}}_{\mathrm{avg}} \text {. As }
$$

dimana,

$$
\mathrm{Qu}=40 . \mathrm{Np} \cdot \mathrm{Ap}+0,2 . \tilde{\mathrm{N}} \cdot \mathrm{As}
$$

$\mathrm{Q}_{\text {ult }}=$ Daya dukung ultimate tiang (ton).

$\mathrm{m}=$ koefisien perlawanan ujung tiang

$\mathrm{Np}=$ nilai NSPT pada ujung tiang

Ap = luas penampang pada dasar tiang $\left(\mathrm{m}^{2}\right)$.

$\mathrm{n} \quad=$ koefisien perlawanan gesek tiang

$\tilde{\mathrm{N}}_{\text {avg }}=$ nilai rata-rata NSPT sepanjang tiang

$$
\text { As = luas selimut tiang. }
$$

\section{- Tanah Kelanauan}

Besarnya daya dukung ultimate tiang sbb,

$$
\mathrm{Qu}=40 . \mathrm{Np} \cdot \mathrm{Ap}+0,5 \cdot \tilde{\mathrm{N}}_{\mathrm{avg}} . \mathrm{As}
$$

\section{Metode L' Decourt}

Menurut L. Decourt (1982) (sumber : Herman

Wahyudi) daya dukung ultimit tiang pancang dinyatakan dengan,

$$
\mathrm{Qu}=\mathrm{Qp}+\mathrm{Qs} \text {. }
$$

Daya dukung ujung (Qp) :

Dimana,

$$
\mathrm{Qp}=\tilde{\tilde{N}} \mathrm{p} . \mathrm{K} \cdot \mathrm{Ap}
$$

$\tilde{\mathrm{N} p}=$ Rata-rata dari harga SPT mulai 4D

di bawah ujung tiang sampai 4D

diatas tiang.

$\mathrm{K}=$ koefisien tanah (pada tabel 3)

Ap = luas penampang dasar tiang

Besarnya daya dukung selimut tiang (Qs) :

Dimana,

$$
\mathrm{Qs}=(\tilde{\mathrm{N}} / 3+1) \text {. As }
$$

$$
\begin{aligned}
& \mathrm{N}=\text { nilai rata-rata NSPT sepanjang tiang } \\
& \mathrm{As}=\text { luas selimut tiang sepanjang tiang tertanam }
\end{aligned}
$$

Tabel 3. Nilai Koefisien Tergantung dari Jenis Tanah

\begin{tabular}{|c|c|}
\hline \multicolumn{2}{|c|}{ Nilai $\mathbf{k}$} \\
\hline Soil type & $\mathbf{K}\left(\mathbf{t} / \mathbf{m}^{\mathbf{2}}\right)$ \\
\hline Clay & 12 \\
\hline Clay silt & 20 \\
\hline Sand silt & 25 \\
\hline Sand & 40 \\
\hline
\end{tabular}

Sumber L’Decourt 1982

\section{Daya Dukung Tiang yang di Izinkan (Qall)}

Berdasarkan beban-beban yang bekerja pada tiang pancang akan mempengaruhi dari tiang pancang itu sendiri baik pada saat pemancangan (terhadap kekuatan tanah) maupun terhadap beban yang bekerja diatasnya. Untuk menjaga agar tiang tetap stabil dalam menerima beban yang bekerja, perlu diketahui kuat dukung tiang yang diizinkan.

$$
\text { Qall }=\frac{\text { Qult }}{S F}
$$

Dimana :

$$
\begin{aligned}
\mathrm{Q}_{\text {all }}= & \text { Daya dukung ijin tiang (ton) } \\
\mathrm{Q}_{\mathrm{ult}}= & \text { Daya dukung ultimit tiang (ton) } \\
\mathrm{SF}= & \text { Faktor keamanan (tersaji dalam } \\
& \text { Tabel 4) }
\end{aligned}
$$

Perhitungan daya dukung atau kapasitas tiang dapat dilakukan dengan cara pendekatan stastis ataupun dinamis. Perhitungan kapasitas tiang dengan metode statis dapat dilakukan menurut teori mekanika tanah, yaitu dengan mempelajari sifat-sifat teknis tanah tersebut sedangkan hitungan kapasitas tiang dengan menggunakan metode dinamis ialah dilakukan dengan menganalisis kapasitas ultimit dengan data yang diperoleh dari data pemancangan tiang. Hasil kapasitas tiang yang didasarkan pada teori mekanika tanah, kadang-kadang masih perlu dicek dengan 
mengadakan pengujian ulang tiang untuk meyakinkan hasilnya.

Faktor Keamanan.

Untuk memperoleh daya dukung izin tiang, maka diperlukan untuk membagi daya dukung ultimit tiang dengan faktor keamanan tertentu. Faktor keamanan ini perlu diberikan dengan maksud sebagai berikut :

1. Untuk memberikan keamanan terhadap ketidakpastian metode hitungan yang digunakan.

2. Untuk memberikan keamanan terhadap variasi kuat geseran kompresibilitas tanah.

3. Untuk meyakinkan bahwa bahan tiang cukup untuk aman dalam mendukung beban yang bekerja.

4. Untuk meyakinkah bahwa penurunan total yang terjadi pada tiang tunggal atau kelompok masih tetap dalam batas-batas toleransi.

5. Untuk meyakinkan bahwa penurunan tidak seragam diantara tiang-tiang masih dalam batas toleransi.

Besarnya kuat dukung ijin $\left(\mathrm{Qa}=\mathrm{Q}_{\text {all }}\right)$ dengan memperhatikan keamanan terhadap keruntuhan adalah nilai kapasitas ultimite $\left(\mathrm{Q}_{\mathrm{ult}}\right)$ dibagi dengan faktor keamanan (SF) yang sesuai. Variasi besarnya faktor keamanan yang telah banyak digunakan untuk perancangan pondasi tiang pancang, sebagai berikut :

$$
S F=\frac{Q u l t}{Q a}
$$

Dimana :

$\mathrm{Qa}=$ Kapasitas dukung ijin tiang (ton)

$\mathrm{Qu}=$ Kapasitas dukung ultimite tiang (ton)

$\mathrm{SF}=$ Faktor keamanan

Penggunaan faktor keamanan minimum yang dipakai dalam perhitungan untuk metode statis dan metode dinamis dapat dilihat Tabel 4.

Tabel 4. Faktor Keamanan minimum

\begin{tabular}{|c|c|}
\hline Metode & $\begin{array}{c}\text { Faktor aman minimum } \\
\text { (SFmin) }\end{array}$ \\
\hline L' Decourt & 3 \\
\hline Mayerhoof & 3 \\
\hline Brown & 3 \\
\hline
\end{tabular}

Sumber :Braja.M.Das

\section{METODOLOGI}

Metodologi penelitian dengan judul "Studi Komparatif Daya Dukung Pondasi Tiang Dengan Teori Meyerhoff Terhadap Teori L'Decourt Berdasar" Hasil Uji N-SPT Di Surabaya Timur disajikan dalam diagram alir sbb :

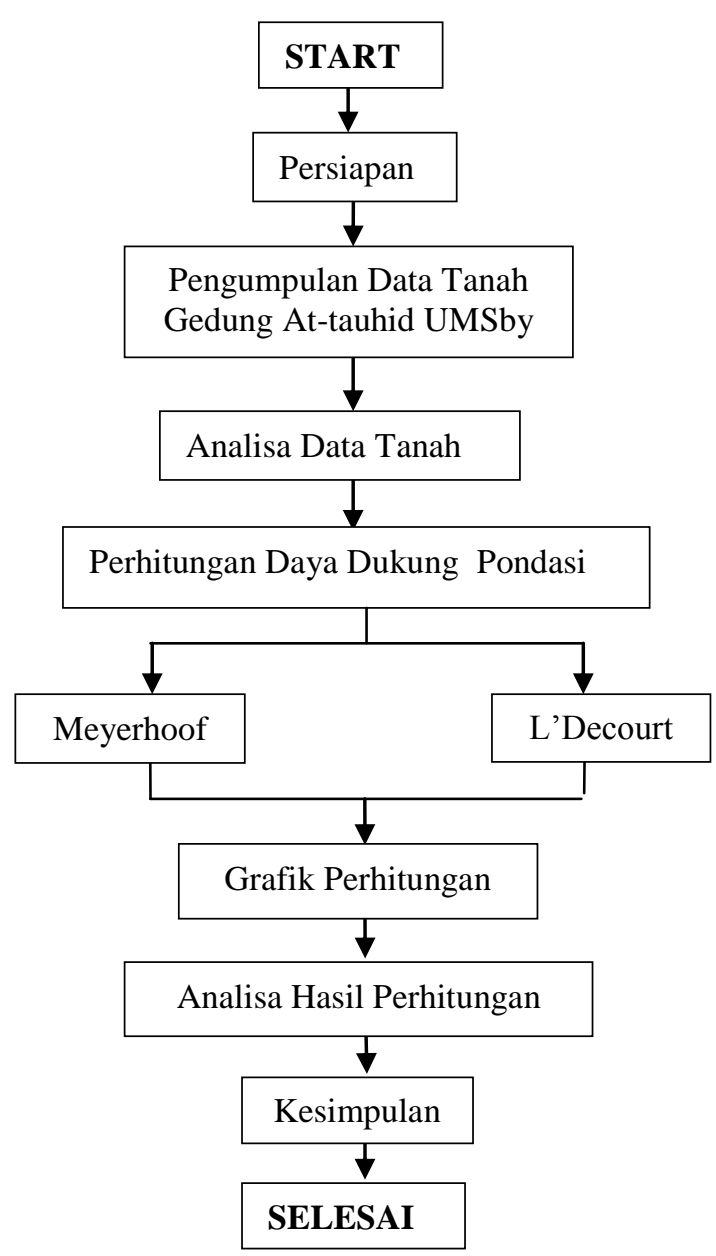

Gambar 2. Diagram Alir Penelitian

\section{GRAFIK DAN ANALISA HASIL PERHITUNGAN Grafik Hasil Perhitungan DB1:}

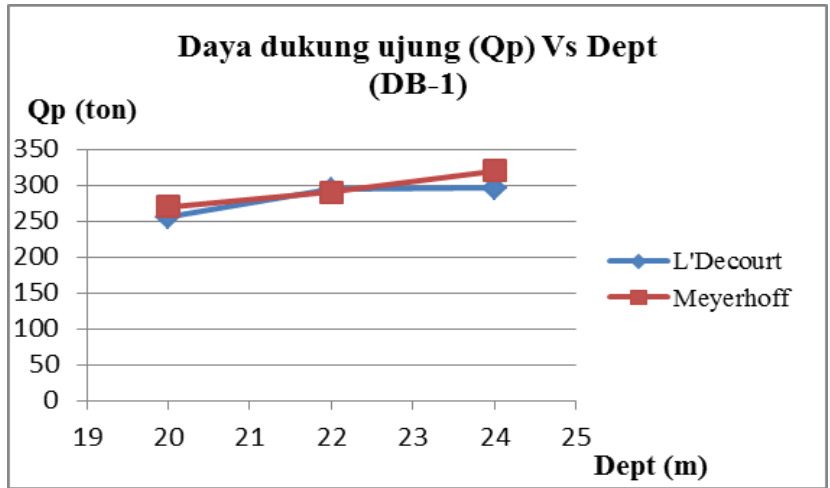

Gambar 3. Grafik Hasil Perhitungan Qp

Terhadap Kedalaman pada DB1

(sumber: hasil perhitungan) 


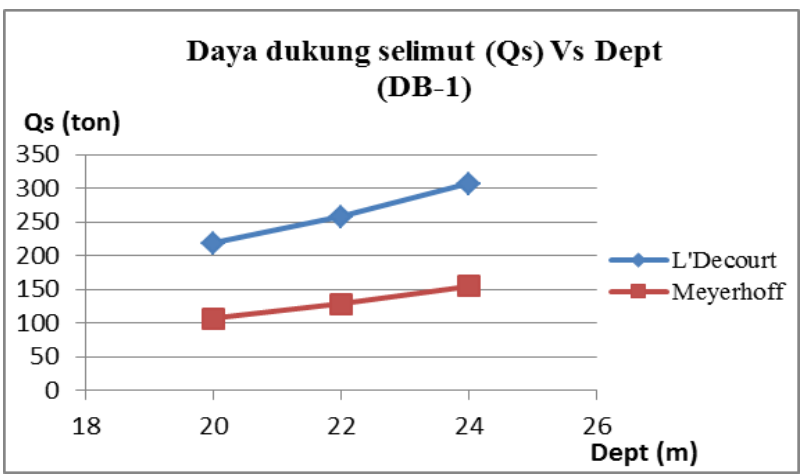

Gambar 4. Grafik Hasil Perhitungan Qs terhadap kedalaman pada DB1

(sumber: hasil perhitungan)

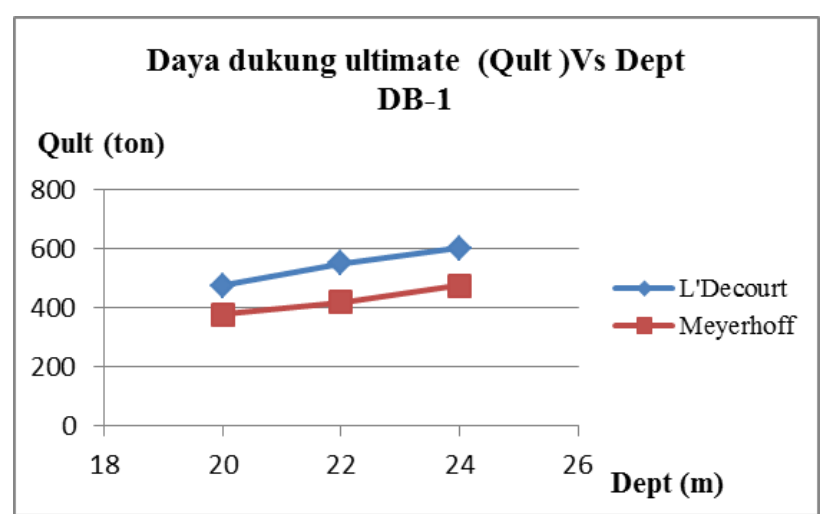

Gambar 5. Grafik Perhitungan Qult Terhadap Kedalaman pada DB 1

(sumber: hasil perhitungan)

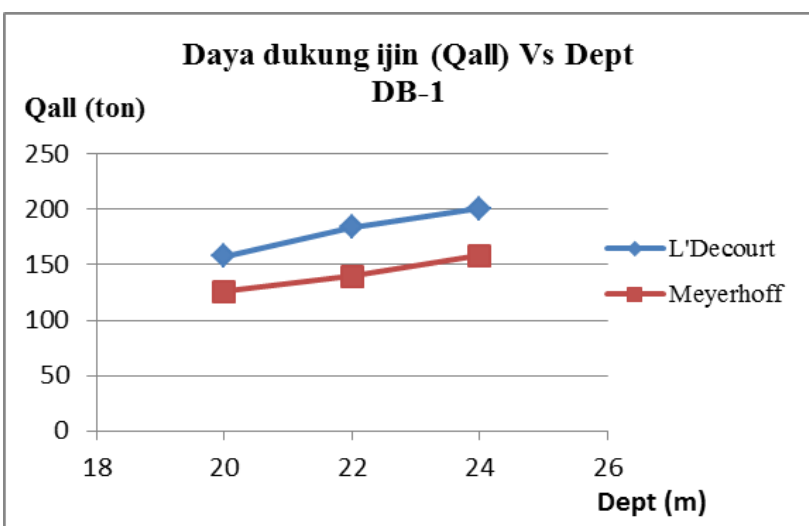

Gambar 6. Grafik Perhitungan Qall Terhadap

Kedalaman pada DB 1

(sumber: hasil perhitungan)

\section{Analisa Daya Dukung Arah Vertikal (DB-I)}

Pada gambar 3 sd 6 adalah grafik titik bor 1 (DB1) yang menunjukkan hubungan antara kedalaman terhadap daya dukung end bearing (Qp), daya dukung selimut (Qs), daya dukung ultimate (Qult), daya dukung ijin (Qall) dengan dianalisa sbb :

1. Pada gambar 3, pada kedalaman yang sama menunjukkan besarnya Qp pada L'Decourt memiliki nilai Qp yang $\approx$ Qp pada Meyerhof hal ini dikarenakan pada kedua teori tersebut (L'Decout \& Meyerhoff) mempunyai koefisien pengali yang sama dari tanah kepasiran yaitu 40 .
2. Pada gambar 4, pada kedalaman yang sama menunjukkan besarnya Qs pada L'Decourt $>$ Qs pada Meyerhof hal ini dikarenakan pada L'Decourt Qs mempunyai koefisien pengali yang lebih besar daripada koefisien pengali pada Meyerhoff

3. Pada gambar 5, pada kedalaman yang sama menunjukkan besarnya Qult pada L'Decourt > Qult pada Meyerhof hal ini dikarenakan nilai Qs pada L'Decourt > nilai Qs pada Meyerhoff

4. Pada gambar 6, pada kedalaman yang sama menunjukkan besarnya Qall pada L'Decourt > Qall pada Meyerhof hal nilai Qult pada L'Decourt > nilai Qult pada Meyerhoff.

\section{Grafik Hasil Perhitungan DB2 :}

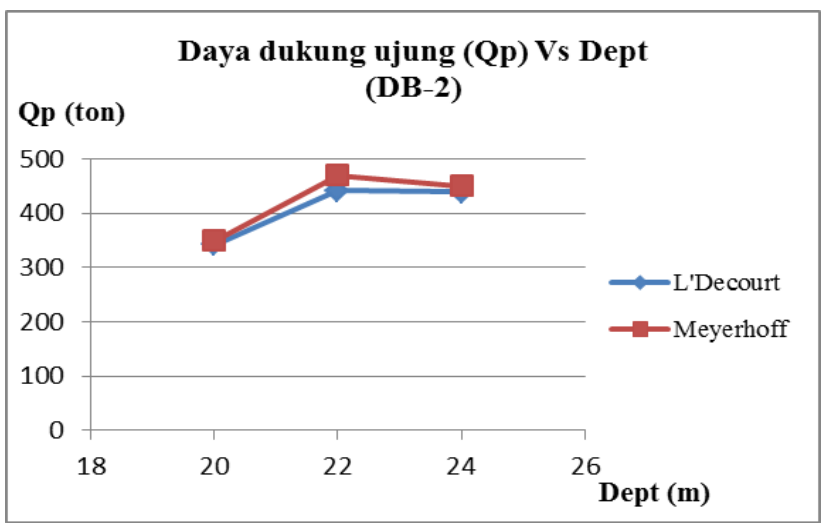

Gambar 7. Grafik Hasil Perhitungan Qp terhadap kedalaman pada DB2

(sumber: hasil perhitungan)

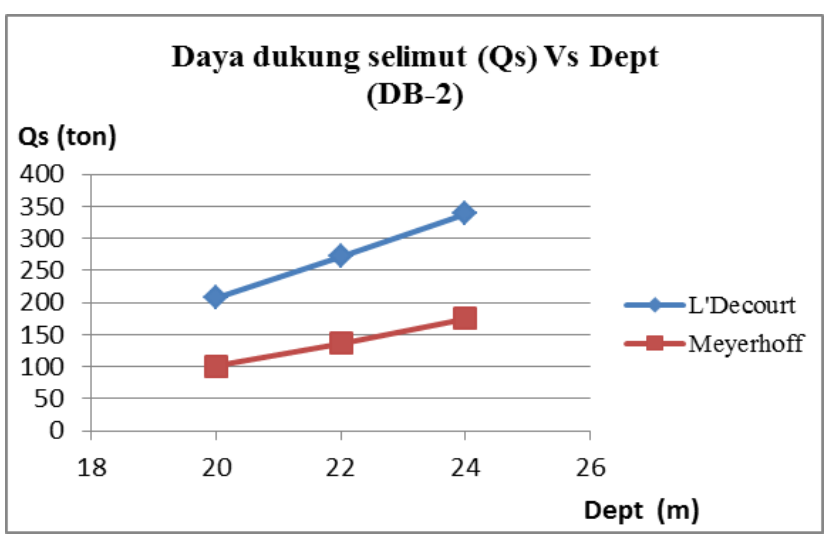

Gambar 8. Grafik Hasil Perhitungan Qs terhadap kedalaman pada DB2 (sumber: hasil perhitungan) 


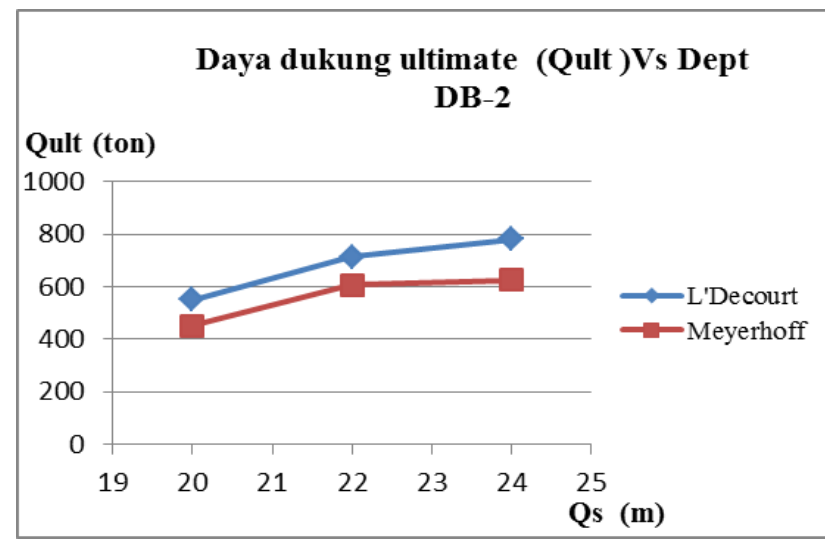

Gambar 9. Grafik Perhitungan Q.Ujung Terhadap Kedalaman pada DB2 (sumber: hasil perhitungan)

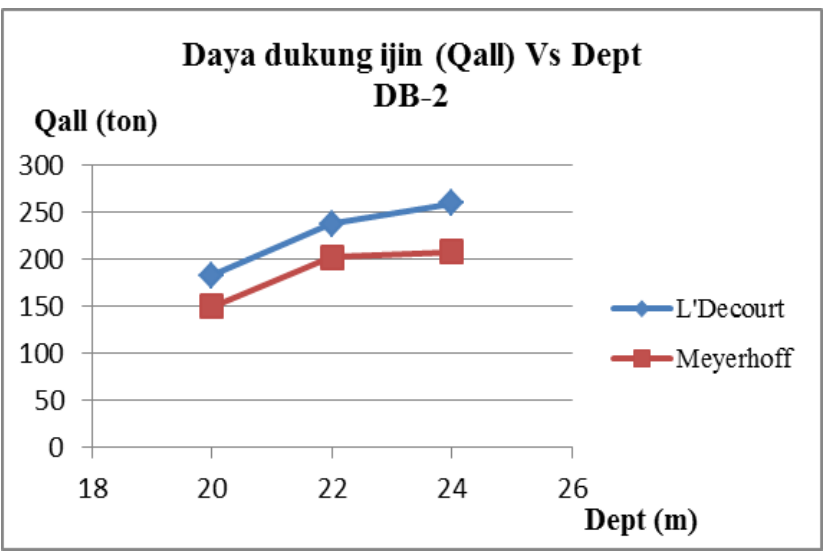

Gambar 10. Grafik Perhitungan Qijin

Terhadap Kedalaman $\left(Q_{\mathrm{P}}\right)$ pada DB2 (sumber: hasil perhitungan)

\section{Analisa Daya Dukung Arah Vertikal (DB2)}

Pada gambar 7 sd 10 adalah grafik titik bor 2 (DB2) yang menunjukkan hubungan antara kedalaman terhadap daya dukung end bearing (Qp), daya dukung selimut (Qs), daya dukung ultimate (Qult), daya dukung ijin (Qall) dengan dianalisa sbb :

1. Pada gambar 7, pada kedalaman yang sama menunjukkan besarnya Qp pada L'Decourt memiliki nilai Qp yang $\approx$ Qp pada Meyerhof, hal ini dikarenakan pada keduateori tersebut (L'Decout \& Meyerhoff) mempunyai koefisien pengali yang sama dari tanah kepasiran yaitu 40 .

2. Pada gambar 8, pada kedalaman yang sama menunjukkan besarnya Qs L'Decourt > Qs pada Meyerhof hal ini dikarenakan pada L'Decourt Qs mempunyai koefisien pengali yang lebih besar daripada koefisien pengali pada Meyerhoff.

3. Pada gambar 9, pada kedalaman yang sama menunjukkan besarnya Qult pada L'Decourt > Qult pada Meyerhof hal ini dikarenakan nilai Qs pada L'Decourt > nilai Qs pada Meyerhoff .

4. Pada gambar 10, pada kedalaman yang sama menunjukkan besarnya Qall pada L'Decourt > Qall pada Meyerhof hal nilai Qult pada L'Decourt > nilai Qult pada Meyerhoff

\section{KESIMPULAN.}

- $\quad$ Pada DB-1 maupun DB-2 daya dukung ujung Qp pada L'Decourt $\approx$ Qult pada Meyerhoff.

- Pada DB-1 maupun DB-2 daya dukung selimut Qs pada L'Decourt > Qs pada Meyerhoff.

- Pada DB-1 maupun DB-2 daya dukung ultimate Qult pada L'Decourt > Qult pada Meyerhoff.

- Pada DB-1 maupun DB-2 daya dukung ultimate Qall pada L'Decourt > Qall pada Meyerhoff.

- Daya dukung terbesar terjadi pada daya dukung ujung (Qp) baik pada DB-1 maupun DB-2 dengan menggunakan teori L'Decourt maupun teori Meyerhoff.

\section{DAFTAR PUSTAKA}

Das. Braja M, (Second Edition), Principles of Foundation Engineering, Company Boston.

Hardiyatmo. H, (2002), Teknik Pondasi 2, Yogyakarta, edisi kedua, beta offset.

Isnaniati. (2016), Minimalisasi Jumlah Tiang Dalam Group Pile Melalui Pemilihan Bentuk Dasar Penampang Pondasi Tiang Pada Tanah Lempung , Jurnal Agregat, vol.1, pp :1-6

Isnaniati, (2016), "Pengaruh bentuk penampang tiang terhadap jumlah tiang dalam grup pile untuk perencanaan pondasi pada tanah lempung berdasar data CPT Surabaya”, Seminar Nasional Teknik Sipil XII-2016, ITS, Januari, Surabaya.

Isnaniati (2017), Kontribusi Bentuk Penampang Tiang Terhadap Beban Maximum yang Diterima Pondasi untuk Perencanaan Pondasi pada Tanah Lempung dengan Data CPT Surabaya, UMSurabaya, Jurnal Agregat, vol.2, pp: 21-27

Meyerhoff, GG, ans Murdock, L.J, (1953), The bearing capacity of foundation, Press Canadian geotechnical, Journal, vol.5, pp 225-244.

Sanglerat, Guy, olivari G, dan Cambau B, (1989), Soalsoal Praktis dalam Mekanika Tanah dan Teknik pondasi, Jakarta : Erlangga

Wahyudi herman, (1999), Daya Dukung Pondasi Dalam, Penerbit ITS, Surabaya. 